\title{
HAPPINESS, SATISFACTION AND SOCIOECONOMIC CONDITIONS: SOME INTERNATIONAL EVIDENCE
}

\author{
Amado Peiró
}

WP-EC 2002-21

Correspondence to: Amado Peiró, Dpto. Análisis Económico, Universitat de Valencia, Campus dels Tarongers, 46022 Valencia, Tel: 96-382 82 56, Fax: 96-382 82 49, E-mail: Amado.Peiró@uv.es

Editor: Instituto Valenciano de Investigaciones Económicas, S.A.

Primera Edición Agosto 2002

Depósito Legal: V-3096-2002

IVIE working papers offer in advance the results of economic research under way in order to encourage a discussion process before sending them to scientific journals for their final publication.

* Universitat de València. 


\title{
HAPPINESS, SATISFACTION AND SOCIOECONOMIC CONDITIONS: SOME INTERNATIONAL EVIDENCE
}

\author{
Amado Peiró
}

\begin{abstract}
This paper examines the relationships between socioeconomic conditions and happiness or satisfaction of individuals in 15 countries. In agreement with earlier studies, age, health and marital status are strongly associated with happiness and satisfaction. In seeming contrast with other studies, unemployment does not appear to be associated with happiness, although it is clearly associated with satisfaction. Income is also strongly associated with satisfaction, but its association with happiness is weaker. These results point to happiness and satisfaction as two distinct spheres of well-being. While the first would be relatively independent of economic factors, the second would be strongly dependent.
\end{abstract}

Keywords: happiness; satisfaction

JEL Classification: A13; I31

\section{RESUMEN}

Este trabajo examina las relaciones entre las condiciones socioeconómicas y la felicidad o la satisfacción de individuos de 15 países. De acuerdo con estudios anteriores, la edad, la salud y el estado civil están fuertemente asociadas con la felicidad y la satisfacción. En contraste aparente con otros estudios, el desempleo no parece estar asociado con la felicidad, aunque lo está claramente con la satisfacción. La renta también está fuertemente asociada con la satisfacción, pero su asociación con la felicidad es más débil. Estos resultados sugieren que la felicidad y la satisfacción constituyen dos ámbitos distintos del bienestar. Mientras que el primero sería relativamente independiente de factores económicos, el segundo dependería fuertemente de estos factores.

Palabras clave: felicidad, satisfacción. 


\section{Introduction}

The pursuit of happiness and satisfaction underlies most human actions and creations. This is also true with regard to the role of economy in human life. Nevertheless, economics has not always given these issues the importance they deserve. The roots of this thoughtlessness trace back to the discredit and fall of utilitarianism. In spite of being an influential trend in economic analysis, it lost most of its prestige at the beginning of the last century due basically to two reasons: the problem of measuring utility, and the development of ordinal theories of utility that eradicated the approaches based on cardinal theories (see, for example, Lewin, 1996, or Kahneman, Wakker and Sarin, 1997).

Nowadays, the paradoxes, anomalies and refutations of ordinal theories of utility have motivated a reassessment of cardinal theories from different approaches. With respect to measurement of utility, numerous surveys have been carried out in the last decades where individuals quantify their happiness and satisfaction. Though one could initially be reluctant to accept these measures of subjective well-being, psychological and sociological studies sanction them (Argyle, 1987, Myers, 1993, or Pavot and Diener, 1993). They are consistent with alternative evaluations (Frank, 1997), and they may be superior to rival concepts (Sumner, 1996, Holländer, 2001).

In this context, economic research has recently begun to analyze the information contained in these surveys from its own perspective. This line of research should contribute to achieve several important goals: i) a firmer establishment of foundations of economics; ii) a reconsideration of economics in its relationship with psychology, sociology, and other fields; iii) to elucidate several important aspects of economics (see, for example, Di Tella, MacCulloch and Oswald, 2001); and iv) to propose alternative economic policies based on the results obtained ( $\mathrm{Ng}, 1987$, Frank, 1997).

Recent empirical research has focused on different factors associated with happiness and satisfaction. In agreement with psychological and sociological studies, economic research has identified a number of personal and social characteristics associated with happiness and satisfaction. Some of the most important are the following: i) health (Veenhoven,1991); ii) age (Oswald,1997); iii) social relationships and, in particular, marital status (Argyle and Martin, 1991, Lee et al. 1999, Blanchflower and Oswald, 2000); and iv) political stability and development (Argyle, 1987, Frey and Stutzer, 2000a and 2000b). 
Two economic factors have also been considered in their relationship with subjective well-being: unemployment and income. With regard to the first, most studies point to unemployment, beyond the consequent loss of income, as a significant source of unhappiness and dissatisfaction (Clark and Oswald, 1994, Winkelmann and Winkelmann, 1995, or Gerlach and Stephan, 1996). With regard to the second, income level seems to be associated with happiness (Veenhoven, 1989). Nevertheless, the evidence on this last issue is mixed, depending on several points. Already in the pioneering contributions of Easterlin (1973 and 1974), individuals of a given country showed a positive relationship between income and happiness, but this relationship disappeared when considering different countries or time series data. Today, there exists a certain consensus in that: i) over time, happiness does not increase significantly with per capita income, at least in developed countries (Easterlin, 1995, Blanchflower and Oswald, 2000); and ii) people in richer countries are happier than people in poorer ones, though the relationship does not seem to be linear (Veenhoven, 1989).

The purpose of this paper is to provide new evidence on the relationship between socioeconomic conditions of individuals from different countries and their degree of happiness and satisfaction, paying special attention to the role of income. To achieve this objective, section 2 presents the data used in this study. Section 3 analyzes these relationships and, in particular, examines the relationship between income, on the one hand, and happiness and satisfaction, on the other hand. Finally, section 4 summarizes the main conclusions.

\section{Data}

The source of data used in this study is the World Values Survey from 1995-1996. The World Values Survey includes representative surveys of basic values of publics in many societies on all inhabited continents. It grew out of surveys carried out in ten western European societies. In 1990-1991 a second wave was carried out and in 1995-1996 the survey covered 54 independent countries. From these countries, information was available for 26 societies, and, among these, 15 were selected according to the basic criteria of quality and availability of information, and geographic diversity. The countries selected, with their sample sizes in parenthesis, are the following: Argentina (1079), Australia 
(2048), Chile (1000), China (1500), Dominican Republic (417), Finland (987), Japan (1054), Nigeria (2769), Peru (1211), Russia (1961), Spain (1211), Sweden (1009), Taiwan (1452), U.S.A. (1542), and Venezuela (1200). These countries cover a considerable proportion of the world's population and present very different economic, social or political characteristics.

The surveys conducted in these countries include questions on happiness and satisfaction of individuals, as well as on their socioeconomic characteristics. Some of the most relevant questions are detailed in Appendix 1. In particular, questions 2, 20 and 21 examine happiness, financial satisfaction, and life satisfaction, respectively, of individuals. These are the main variables that will be studied here. The answers to 20 and 21 range from 1 (completely dissatisfied) to 10 (completely satisfied). The possible answers to 2 range from 1 (very happy) to 4 (not at all happy), but in order to get an ordering analogous to the other questions, these answers have been recoded from 1 (not at all happy) to 4 (very happy).

Table 1 shows some basic statistics on happiness, financial satisfaction and life satisfaction. There are clear differences in these statistics across countries; Russia presents the lowest mean in happiness (2.50), very far from that of Venezuela (3.48), which presents the highest. Russia also has the lowest means in the two other variables while the highest correspond to developed countries (Finland and USA, in financial satisfaction, and Finland and Sweden, in life satisfaction). The anomalous statistics obtained for Russia are common to other studies, and are discussed in Veenhoven (2001). Table 1 also shows that all correlations between these measures of subjective well-being are positive and clearly significant. They are always lower between happiness and financial satisfaction, and are usually higher between financial satisfaction and life satisfaction than between happiness and life satisfaction. Very similar results were obtained with other non-parametric measures of association, like Kendall's or Spearman's rank correlations. In the interpretation of these results, it is important to bear in mind two points. Firstly, though the concepts of happiness and life satisfaction may seem very similar, they present differences; according to psychological studies, happiness would be an emotional or affective state, while satisfaction would entail a cognitive process. Secondly, the questions on financial and life satisfaction were consecutive, and were both quite distant from the question on happiness. This fact could also affect subsequent results that will be analyzed later. 
Table 1. Basic statistics

\begin{tabular}{|l|c|c|c|c|c|c|c|c|c|}
\hline & \multicolumn{2}{|c|}{ Happiness (H) } & \multicolumn{3}{c|}{ Financial } & \multicolumn{2}{c|}{ Life Satisfaction } & \multicolumn{3}{c|}{ Correlations } \\
& Mean & S.D. & Mean & S.D. & Mean & S.D. & H, FS & H,LS & FS, LS \\
\hline ARGENTINA & 3.10 & 0.72 & 4.96 & 2.50 & 6.93 & 2.31 & 0.27 & 0,50 & 0,40 \\
\hline AUSTRALIA & 3.37 & 0.62 & 6.40 & 2.39 & 7.58 & 1.88 & 0,24 & 0,51 & 0,48 \\
\hline CHILE & 3.07 & 0.70 & 5.91 & 2.27 & 6.92 & 2.14 & 0,29 & 0,39 & 0,48 \\
\hline CHINA & 3.05 & 0.66 & 6.11 & 2.45 & 6.83 & 2.42 & 0,38 & 0,45 & 0,71 \\
\hline DOMINICAN REP. & 3.05 & 0.78 & 5.74 & 2.92 & 7.13 & 2.47 & 0,12 & 0,29 & 0,51 \\
\hline FINLAND & 3.15 & 0.57 & 6.65 & 2.20 & 7.78 & 1.55 & 0,24 & 0.51 & 0.47 \\
\hline JAPAN & 3.23 & 0.63 & 6.33 & 2.02 & 6.61 & 1.90 & 0.37 & 0.43 & 0.67 \\
\hline NIGERIA & 3.23 & 0.84 & 5.92 & 2.84 & 6.82 & 2.62 & 0.28 & 0.33 & 0.56 \\
\hline PERU & 2.91 & 0.82 & 5.12 & 2.52 & 6.36 & 2.43 & 0.16 & 0.27 & 0.43 \\
\hline RUSSIA & 2.50 & 0.73 & 3.30 & 2.26 & 4.45 & 2.52 & 0.34 & 0.47 & 0.58 \\
\hline SPAIN & 3.05 & 0.59 & 5.64 & 2.04 & 6.61 & 1.97 & 0.25 & 0.36 & 0.50 \\
\hline SWEDEN & 3.34 & 0.60 & 6.26 & 2.43 & 7.77 & 1.81 & 0.30 & 0.57 & 0.43 \\
\hline TAIWAN & 3.14 & 0.63 & 6.33 & 2.15 & 6.89 & 2.03 & 0.32 & 0.40 & 0.63 \\
\hline USA & 3.40 & 0.63 & 6.56 & 2.51 & 7.67 & 2.01 & 0.28 & 0.49 & 0.53 \\
\hline VENEZUELA & 3.48 & 0.64 & 5.00 & 3.11 & 6.72 & 3.00 & 0.14 & 0.19 & 0.47 \\
\hline
\end{tabular}

Basic statistics on happiness, financial satisfaction and life satisfaction. All the correlations are significant at the usual significance levels.

\section{Happiness, satisfaction and socioeconomic conditions}

To elucidate the causes and factors that underlie happiness and satisfaction of people in the different countries, ordered logit models were estimated. The dependent variables in these models are reported happiness, financial satisfaction and life satisfaction. Among the explanatory variables, several personal, demographic and economic characteristics were included. Appendix 2 details these variables. Not all of them were available in the same way for all countries; this issue is also briefly commented on in Appendix 2.

Tables 2, 3 and 4 show the results of these regressions in the different countries for happiness, financial satisfaction and life satisfaction, respectively. The analysis of the particular influence of each of the twenty-six variables in each of the three dependent variables and in each of the fifteen countries would be a prolix task. Instead, the analysis will focus on those results that are common to several countries. While the results for each country are reported below, the practice of focusing on common results has the advantage of studying general facts, rather than analyzing specific or peculiar features of one country. 
Table 2. Ordered logit models for happiness

\begin{tabular}{|c|c|c|c|c|c|c|c|c|c|c|c|c|c|c|c|}
\hline & ARGEN & AUSTL & CHILE & CHINA & DOM. R. & FINLAN & JAPAN & NGERIA & PERU & RUSSIA & SPAIN & SWEDN & TAIWN & USA & VENEZ \\
\hline AGE & $-0.059 *$ & $-0.067 * *$ & -0.044 & $-0.056^{*}$ & -0.066 & $-0.170^{* *}$ & -0.063 & $-0.060^{*}$ & -0.026 & $-0.097 * *$ & $-0.079 * *$ & -0.058 & 0.012 & -0.013 & 0.007 \\
\hline$A G E^{2}(\%)$ & 0.050 & $0.072 * *$ & 0.041 & $0.075^{*}$ & 0.132 & $0.168^{* *}$ & 0.067 & $0.071 *$ & 0.046 & $0.093 * *$ & $0.082 * *$ & 0.051 & -0.027 & 0.018 & -0.013 \\
\hline BADHEALTH & $-0.990 * *$ & $-1.270^{* *}$ & $-1.281^{* *}$ & $-1.245^{* *}$ & $-3.930 * *$ & $-1.964 * *$ & $-1.430^{* * *}$ & $-1.659 * *$ & $-0.949 *$ & $-1.286^{* *}$ & $-1.174 * *$ & $-1.783^{* *}$ & $-0.961 * *$ & $-1.294 * *$ & $-0.809^{* *}$ \\
\hline WOMAN & -0.074 & $0.402 * *$ & -0.262 & $0.404 * *$ & -0.070 & $0.474 * *$ & $0.467 * *$ & $0.246^{*}$ & 0.245 & -0.019 & 0.073 & $0.387^{*}$ & 0.183 & 0.040 & -0.212 \\
\hline 1 CHILD & -0.117 & 0.022 & 0.302 & 0.220 & -0.068 & \begin{tabular}{|l|}
-0.287 \\
\end{tabular} & 0.054 & 0.148 & -0.392 & 0.141 & -0.298 & 0.138 & $0.945^{*}$ & -0.077 & -0.165 \\
\hline 2CHILDREN & 0.145 & 0.012 & -0.095 & 0.320 & -0.897 & -0.057 & -0.168 & 0.386 & -0.426 & 0.213 & 0.024 & 0.346 & 0.575 & -0.275 & $-0.515^{*}$ \\
\hline 3CHILDREN & 0.214 & -0.016 & 0.151 & -0.015 & -0.542 & 0.063 & 0.154 & $0.656^{*}$ & $-0.787 * *$ & $0.733^{* *}$ & -0.264 & 0.408 & 0.761 & $-0.497 *$ & -0.343 \\
\hline$>3$ CHILDREN & -0.228 & 0.053 & 0.529 & -0.237 & $-1.716^{* *}$ & 0.096 & 0.275 & 0.460 & $-0.998 * *$ & $0.680^{*}$ & -0.315 & 0.729 & $0.926^{*}$ & -0.391 & -0.379 \\
\hline MARRIED & $0.666^{* * *}$ & $0.788^{* *}$ & 0.355 & 0.078 & 0.117 & $0.533^{*}$ & $1.402 * *$ & -0.187 & 0.229 & $0.581^{* *}$ & $0.688^{*}$ & $0.549 *$ & -0.209 & $0.877 * *$ & 0.218 \\
\hline WIDOWED & 0.434 & -0.416 & -0.331 & 0.299 & 0.488 & -0.252 & $1.194 *$ & -0.888 & 0.457 & -0.333 & $-1.021^{*}$ & -0.837 & -0.912 & 0.234 & -0.449 \\
\hline SEPARATED & -0.015 & -0.277 & $-0.656^{*}$ & -0.749 & -0.562 & -0.391 & 0.674 & $-0.903 *$ & $-0.727^{*}$ & -0.433 & -0.645 & $-0.775^{*}$ & -0.631 & -0.068 & -0.056 \\
\hline TOWN2 & & -0.105 & & -0.130 & 0.189 & & -0.068 & 0.021 & 0.206 & 0.222 & 0.145 & 0.099 & -0.170 & -0.226 & $-0.829 * *$ \\
\hline TOWN3 & & -0.240 & 0.055 & 0.123 & -0.032 & & & 0.231 & 1.160 & 0.220 & -0.022 & 0.302 & -0.323 & -0.132 & $-0.496 *$ \\
\hline TOWN4 & & -0.178 & & $0.478^{* *}$ & -0.290 & & & 0.230 & 0.960 & 0.185 & -0.157 & & & $-0.428^{*}$ & -0.291 \\
\hline PRIMARY & & & -0.005 & -0.275 & & 0.234 & & -0.236 & & 0.822 & 0.516 & & 0.419 & & 0.011 \\
\hline SECUNDARY & -0.368 & $0.502 *$ & -0.417 & 0.176 & -0.262 & 0.227 & & -0.107 & 0.053 & 0.903 & 0.621 & -0.084 & $0.977 * *$ & -0.317 & 0.067 \\
\hline UNIVERSITY & -0.005 & 0.126 & -0.553 & 0.009 & 0.065 & & & 0.142 & 0.130 & 1.053 & 0.663 & 0.432 & $1.294 * *$ & -0.336 & 0.040 \\
\hline PARTTIME & 0.195 & -0.077 & 0.276 & $-0.396^{*}$ & 0.135 & -0.354 & -0.319 & -0.072 & 0.060 & 0.130 & -0.026 & -0.184 & 0.092 & $-0.414 *$ & 0.023 \\
\hline SELFEMPLOYED & -0.124 & -0.334 & -0.099 & 0.245 & -0.088 & -0.213 & -0.305 & 0.102 & -0.322 & -0.375 & -0.004 & 0.297 & 0.157 & 0.370 & -0.029 \\
\hline HOUSEWIFE & -0.068 & -0.085 & 0.128 & -0.391 & 0.070 & 0.407 & 0.453 & -0.149 & 0.117 & 0.328 & -0.147 & -1.008 & 0.253 & $0.466^{*}$ & 0.380 \\
\hline STUDENT & 0.054 & $0.737 *$ & 0.309 & 0.057 & -0.116 & 0.590 & -0.441 & 0.049 & -0.447 & $0.833^{*}$ & -0.401 & 0.458 & -0.111 & -0.149 & -0.141 \\
\hline UNEMPLOYED & 0.079 & & -0.354 & -0.115 & -0.636 & -0.243 & 1.430 & 0.032 & -0.046 & -0.375 & -0.206 & -0.360 & -0.772 & -0.127 & -0.118 \\
\hline$I Q 2$ & $0.449^{*}$ & 0.140 & 0.340 & $0.714 * *$ & -0.302 & 0.236 & 0.234 & -0.108 & 0.235 & $0.368^{* *}$ & 0.177 & $0.587^{*}$ & 0.351 & -0.141 & 0.147 \\
\hline$I Q 3$ & $0.504 *$ & $0.504 * *$ & $0.745^{* *}$ & $1.349 * *$ & -0.389 & $0.851 * *$ & $0.604 * *$ & -0.038 & -0.002 & $0.422 * *$ & 0.359 & $0.753 *$ & 0.374 & 0.333 & 0.173 \\
\hline$I Q 4$ & 0.385 & $0.413^{*}$ & $1.112^{* *}$ & $1.921^{* *}$ & -0.256 & 0.565 & $0.741 * *$ & 0.222 & 0.116 & $0.842 * *$ & 0.013 & $0.716^{*}$ & $0.459^{*}$ & 0.289 & 0.143 \\
\hline IQ5 & 0.443 & $0.515^{* *}$ & $0.994 * *$ & $1.704 * *$ & 0.256 & $1.187^{* * *}$ & $1.108^{* *}$ & $0.566^{*}$ & 0.929 & $1.213^{* *}$ & 0.628 & $0.931 *$ & $0.677^{* *}$ & 0.474 & 0.129 \\
\hline$N$ & 757 & 1715 & 922 & 1473 & 295 & 885 & 833 & 1416 & 952 & 1881 & 871 & 796 & 1027 & 1244 & 1119 \\
\hline$P_{\text {seudo- }} R^{2}(\%)$ & 3.4 & 5.4 & 5.9 & 8.0 & 5.0 & 10.7 & 7.6 & 3.2 & 2.7 & 10.7 & 5.2 & 6.9 & 9.3 & 5.3 & 2.8 \\
\hline
\end{tabular}

Estimates of coefficients in ordered logit models for happiness. * and ** denote significance at the $5 \%$ and $1 \%$ significance level, respectively. $N$ denotes the sample size. See Appendix 2 for more details on the explanatory variables. 
Table 3. Ordered logit models for financial satisfaction

\begin{tabular}{|c|c|c|c|c|c|c|c|c|c|c|c|c|c|c|c|}
\hline & ARGEN & AUSTL & CHILE & CHINA & DOM. R. & FINLAN & JAPAN & NGERIA & PERU & RUSSIA & SPAIN & SWEDN & TAIWN & USA & VENEZ \\
\hline AGE & $-0.063^{*}$ & $-0.096^{* *}$ & -0.042 & $-0.068^{* *}$ & $-0.353^{* *}$ & $-0.071^{* *}$ & $-0.100^{* *}$ & -0.011 & $-0.082^{*}$ & $-0.061 * *$ & -0.043 & $-0.077 *$ & 0.055 & $-0.044 *$ & -0.034 \\
\hline$A G E^{2}(\%)$ & $0.072 *$ & $0.140^{* *}$ & 0.042 & $0.080^{* *}$ & $0.459^{* *}$ & $0.121 * *$ & $0.122^{* *}$ & 0.018 & $0.086^{*}$ & $0.077^{* *}$ & $0.050^{*}$ & $0.111^{* *}$ & -0.049 & $0.080^{* *}$ & 0.034 \\
\hline BADHEALTH & -0.464 & $-1.011 * *$ & $-0.709 * *$ & $-1.004 * *$ & -2.479 & $-0.897 * *$ & $-0.792 * *$ & $-1.392 * *$ & $-1.227 * *$ & $-0.731^{* *}$ & $-0.658^{* *}$ & $-1.113 * *$ & $-0.940 * *$ & $-0.624 *$ & -0.830 ** \\
\hline WOMAN & $-0.317 *$ & -0.106 & -0.210 & 0.187 & $-0.538^{*}$ & 0.214 & 0.032 & $0.323^{* *}$ & -0.093 & -0.130 & 0.149 & -0.130 & $0.266^{*}$ & 0.034 & -0.109 \\
\hline 1 1CHILD & $\begin{array}{l}-0.358 \\
\end{array}$ & -0.314 & 0.119 & 0.487 & $\begin{array}{l}-0.297 \\
\end{array}$ & $-0.512 *$ & 0.048 & -0.201 & -0.135 & 0.006 & 0.080 & -0.360 & -0.129 & $-0.699 * *$ & -0.330 \\
\hline 2CHILDREN & -0.250 & $-0.380^{*}$ & -0.203 & 0.555 & 0.106 & $-0.430^{*}$ & -0.266 & 0.070 & 0.044 & -0.146 & 0.090 & $-0.688^{* *}$ & -0.330 & $-0.568 * *$ & $-0.396^{*}$ \\
\hline 3CHILDREN & -0.458 & $-0.425^{* *}$ & -0.238 & 0.316 & 0.096 & $-0.646^{* *}$ & -0.148 & -0.029 & -0.125 & -0.448* & 0.070 & $-0.903 * *$ & -0.158 & $-0.594 * *$ & -0.378 \\
\hline$>3$ CHILDREN & -0.694* & $\begin{array}{l}-0.282 \\
\end{array}$ & -0.244 & $0.688^{*}$ & 0.532 & $-0.586^{*}$ & 0.000 & -0.070 & -0.458 & 0.275 & -0.013 & -0.178 & -0.197 & $-0.835^{* *}$ & -0.254 \\
\hline MARRIED & 0.239 & $0.467 * *$ & 0.363 & -0.303 & 0.566 & 0.013 & 0.085 & -0.138 & 0.023 & -0.129 & -0.085 & $0.641^{* *}$ & -0.011 & $0.616^{* *}$ & $0.317 *$ \\
\hline WIDOWED & 0.448 & -0.013 & -0.050 & 0.064 & -1.446 & 0.205 & 0.904 & -0.418 & -0.190 & 0.069 & -0.553 & 0.474 & -0.335 & 0.197 & 0.042 \\
\hline SEPARATED & -0.224 & $-0.404 *$ & 0.009 & -0.226 & 0.200 & -0.332 & -0.644 & -0.213 & -0.445 & -0.203 & $-1.453^{* *}$ & 0.098 & -0.521 & -0.224 & 0.183 \\
\hline TOWN2 & & -0.006 & & -0.053 & -1.059 & & 0.198 & $-0.724 * *$ & 0.362 & 0.116 & -0.048 & 0.075 & 0.799 ** & -0.116 & $0.902 * *$ \\
\hline TOWN3 & & -0.079 & -0.251 & 0.060 & 0.489 & & & $-0.579 * *$ & 0.071 & 0.178 & 0.265 & -0.127 & $0.651^{* *}$ & -0.153 & $0.391 *$ \\
\hline TOWN4 & & $-0.308^{*}$ & & 0.278 & -0.571 & & & $-0.540^{* *}$ & 0.814 & 0.015 & -0.233 & & & -0.462** & $0.608^{* * *}$ \\
\hline PRIMARY & & & 0.734 & 0.105 & & 0.253 & & -0.202 & & 1.198 & 0.033 & & 0.020 & & 0.322 \\
\hline SECUNDARY & $-0.344 *$ & -0.410 & 0.750 & 0.121 & -0.930 & 0.261 & & -0.088 & -0.232 & $1.445^{*}$ & 0.206 & 0.027 & $0.609 *$ & -0.097 & 0.170 \\
\hline UNIVERSITY & 0.045 & -0.428 & 0.520 & 0.324 & 0.286 & & & 0.372 & -0.080 & $1.642 *$ & 0.334 & 1.584 & $0.750^{*}$ & -0.083 & 0.296 \\
\hline PARTTIME & 0.291 & -0.017 & 0.165 & -0.021 & -0.208 & -0.033 & -0.140 & -0.168 & -0.158 & 0.100 & -0.273 & 0.042 & -0.110 & -0.033 & -0.173 \\
\hline SELFEMPLOYED & -0.127 & 0.048 & -0.234 & 0.050 & -0.645 & 0.392 & -0.196 & $0.310^{*}$ & 0.183 & 0.213 & $0.060^{* *}$ & -0.183 & 0.076 & -0.294 & -0.167 \\
\hline HOUSEWIFE & -0.278 & 0.097 & 0.010 & -0.276 & 0.211 & -0.026 & $0.528^{*}$ & 0.190 & 0.299 & -0.023 & -0.231 & 0.724 & $0.475^{* *}$ & 0.246 & -0.240 \\
\hline STUDENT & 0.259 & 0.045 & 0.206 & -0.168 & -0.579 & -0.238 & -0.501 & 0.324 & 0.052 & 0.059 & -0.014 & 0.026 & 0.146 & -0.520 & -0.068 \\
\hline UNEMPLOYED & -0.013 & & $-0.777^{* *}$ & -0.189 & -0.411 & $-0.622^{* *}$ & -0.683 & 0.343 & -0.216 & $-0.491 * *$ & $-0.676^{* *}$ & $-0.994 * *$ & $-0.751^{*}$ & 0.149 & -0.278 \\
\hline$I Q 2$ & $0.667 * *$ & $0.525 * *$ & $0.669 * *$ & $1.203 * *$ & -0.337 & $0.578 * *$ & 0.186 & $0.593 * *$ & $0.452 * *$ & $0.416^{* *}$ & 0.234 & $0.796 * *$ & 0.133 & 0.436 & 0.171 \\
\hline$I Q 3$ & $1.281^{* *}$ & $1.137 * *$ & $0.819 * *$ & $2.201 * *$ & 0.592 & $1.061^{* *}$ & $0.861 * *$ & $0.785^{* *}$ & $0.770 * *$ & $1.115^{* *}$ & $0.820^{* *}$ & $1.340^{* *}$ & $0.397^{*}$ & $1.134 * *$ & $0.520^{* *}$ \\
\hline$I Q 4$ & $1.352 * *$ & $1.294 * *$ & $1.245 * *$ & $2.968 * *$ & 0.445 & $1.192 * *$ & $1.137^{* *}$ & $1.599 * *$ & $1.309 * *$ & $1.417 * *$ & $1.092 * *$ & $1.728 * *$ & $0.434 *$ & $1.459 * *$ & $1.017 * *$ \\
\hline$I Q 5$ & $1.686^{* *}$ & $1.898 * *$ & $2.273^{* * *}$ & $3.655^{* *}$ & $1.481 * *$ & $2.008 * *$ & $1.890 * *$ & $2.469 * *$ & $1.444 *$ & $2.149 * *$ & $1.814 * *$ & $2.529 * *$ & $0.897 * *$ & $2.150 * *$ & 0.675 \\
\hline $\bar{N}$ & 761 & 1713 & 924 & 1478 & 295 & 892 & 822 & 1416 & 935 & $\begin{array}{ll}1911 \\
\end{array}$ & 873 & 801 & 1027 & 1248 & 11123 \\
\hline$P_{\text {seudo- }}{ }^{2}(\%)$ & 3.8 & 5.5 & 4.5 & 6.1 & 7.7 & 6.1 & 4.2 & 4.6 & 2.4 & 4.9 & 3.4 & 5.8 & 3.8 & 6.2 & 2.0 \\
\hline
\end{tabular}

Estimates of coefficients in ordered logit models for financial satisfaction. $*$ and $* *$ denote significance at the $5 \%$ and $1 \%$ significance level, respectively. $N$ denotes the sample size. See Appendix 2 for more details on the explanatory variables. 
Table 4. Ordered logit models for life satisfaction

\begin{tabular}{|c|c|c|c|c|c|c|c|c|c|c|c|c|c|c|c|}
\hline & ARGEN & AUSTL & CHILE & CHINA & DOM. R. & FINLAN & JAPAN & NGERIA & PERU & RUSSIA & SPAIN & SWEDN & TAIWN & USA & VENEZ \\
\hline AGE & $-0.064 *$ & $-0.076 * *$ & 0.011 & $-0.064 * *$ & -0.126 & $-0.116^{* *}$ & $-0.096^{* *}$ & -0.008 & -0.038 & $-0.094 * *$ & $-0.102 * *$ & $-0.089^{* *}$ & 0.017 & $-0.041 *$ & -0.024 \\
\hline$A G E^{2}(\%)$ & $0.060^{*}$ & $0.095^{* *}$ & -0.016 & $0.077^{* *}$ & 0.161 & $0.129 * *$ & $0.108^{* *}$ & 0.016 & 0.060 & $0.098^{* *}$ & $0.100^{* *}$ & $0.092 * *$ & -0.010 & $0.056^{* *}$ & 0.017 \\
\hline BADHEALTH & $-1.266^{* * *}$ & $-1.791 * *$ & -0.486 & $-1.143 * *$ & $-2.379 *$ & $-1.842 * *$ & $-0.925 * *$ & $-1.101^{* *}$ & $-1.413 * *$ & $-0.788^{* *}$ & $-0.821^{* *}$ & $-2.096 * *$ & $-0.982 * *$ & $-0.778^{* *}$ & $-0.746^{* *}$ \\
\hline WOMAN & 0.035 & $0.328 * *$ & -0.238 & $0.200^{*}$ & -0.297 & $0.776^{* *}$ & -0.017 & $0.317 * *$ & 0.061 & -0.095 & 0.126 & 0.129 & $0.338^{*}$ & 0.191 & 0.017 \\
\hline 1 CHILD & 0.109 & 0.179 & 0.098 & 0.376 & -0.050 & $-0.461^{*}$ & -0.011 & -0.319 & -0.307 & 0.054 & -0.075 & 0.312 & 0.105 & -0.259 & 0.269 \\
\hline 2CHILDREN & -0.038 & -0.065 & -0.379 & 0.489 & -0.104 & -0.238 & -0.293 & -0.456 & $-0.641^{* *}$ & -0.010 & 0.059 & 0.131 & -0.385 & $-0.434 *$ & -0.243 \\
\hline 3CHILDREN & -0.096 & 0.032 & -0.221 & 0.285 & 0.251 & -0.190 & -0.270 & -0.463 & $-0.597 *$ & 0.163 & 0.084 & 0.117 & -0.212 & $-0.433^{*}$ & -0.092 \\
\hline$>3$ CHILDREN & 0.305 & 0.309 & 0.030 & 0.536 & -0.336 & -0.068 & -0.087 & -0.510 & $-0.650^{*}$ & $0.603 *$ & -0.166 & 0.524 & -0.425 & -0.248 & -0.057 \\
\hline MARRIED & $0.501^{*}$ & $0.719 * *$ & $0.448^{*}$ & -0.020 & 0.310 & 0.237 & 0.456 & 0.256 & $0.549 * *$ & 0.059 & $0.498^{*}$ & 0.152 & 0.462 & $0.769^{* *}$ & $0.413 * *$ \\
\hline WIDOWED & 0.402 & 0.210 & 0.223 & 0.516 & 0.463 & -0.044 & 0.852 & -0.666 & -0.220 & -0.207 & -0.390 & 0.045 & -0.554 & -0.085 & 0.515 \\
\hline SEPARATED & 0.153 & -0.354 & -0.154 & -0.232 & -0.106 & -0.240 & -0.206 & -0.312 & -0.026 & -0.351 & -0.140 & $-0.768^{* *}$ & -0.219 & -0.294 & 0.148 \\
\hline TOWN2 & & 0.066 & & -0.039 & 0.355 & & 0.003 & $-1.022^{* * *}$ & $0.582 * *$ & 0.193 & 0.300 & -0.042 & $1.020^{* *}$ & -0.222 & $-0.450^{*}$ \\
\hline TOWN3 & & -0.212 & -0.182 & 0.176 & $1.353^{*}$ & & & $-0.461 * *$ & -0.172 & 0.162 & 0.053 & -0.238 & $0.674 * *$ & $-0.372 *$ & $-0.718^{* *}$ \\
\hline TOWN4 & & -0.131 & & 0.182 & -0.169 & & & $-0.542^{* *}$ & -0.485 & 0.147 & 0.020 & & & $-0.577^{* *}$ & -0.150 \\
\hline PRIMARY & & & 0.636 & 0.185 & & 0.142 & & 0.025 & & 0.758 & -0.110 & & 0.110 & & -0.417 \\
\hline SECUNDARY & $.458^{* *}$ & -0.274 & 0.415 & 0.306 & $-1.445^{*}$ & 0.209 & & 0.320 & 0.178 & 0.985 & -0.079 & -0.083 & 0.486 & -0.160 & -0.544 \\
\hline UNIVERSITY & -0.231 & -0.401 & 0.314 & 0.430 & -0.860 & & & $0.646^{* *}$ & 0.274 & 1.127 & 0.121 & 0.368 & 0.389 & -0.052 & -0.559 \\
\hline PARTTIME & 0.106 & -0.173 & 0.433 & -0.147 & 0.012 & -0.274 & -0.080 & -0.182 & -0.153 & -0.015 & $-0.528^{*}$ & -0.129 & -0.053 & -0.199 & -0.191 \\
\hline SELFEMPLOYED & -0.091 & -0.353 & 0.071 & 0.198 & -0.321 & 0.027 & -0.177 & 0.149 & -0.174 & 0.189 & $0.078^{* *}$ & 0.335 & -0.012 & 0.137 & -0.193 \\
\hline HOUSEWIFE & 0.073 & -0.118 & 0.019 & -0.250 & -0.339 & 0.112 & $0.490^{*}$ & -0.350 & 0.141 & 0.182 & -0.038 & 0.186 & 0.328 & -0.007 & -0.150 \\
\hline STUDENT & 0.501 & 0.197 & 0.376 & -0.013 & -0.201 & 0.439 & -0.329 & -0.026 & -0.002 & $0.661 *$ & -0.009 & 0.076 & -0.315 & -0.038 & -0.204 \\
\hline UNEMPLOYED & 0.258 & & $-0.577^{*}$ & 0.220 & -1.064 & $-0.395^{*}$ & -0.089 & 0.257 & 0.077 & $-0.457^{*}$ & $-0.651^{* *}$ & $-0.877^{* *}$ & $-1.220^{* *}$ & $-0.460^{*}$ & $-0.670^{* *}$ \\
\hline$I Q 2$ & $0.506^{*}$ & $0.299 *$ & $0.576^{* *}$ & $0.995^{* *}$ & -0.254 & $0.415^{*}$ & 0.332 & $0.491^{* *}$ & $0.395^{* *}$ & $0.332 * *$ & 0.165 & 0.101 & $0.437^{*}$ & 0.164 & 0.160 \\
\hline$I Q 3$ & $0.535^{* *}$ & $0.625^{* *}$ & $0.645^{* *}$ & $1.634^{* *}$ & -0.040 & $0.888^{* *}$ & $1.037^{* *}$ & $0.474 * *$ & 0.229 & $0.588^{* *}$ & $0.416^{*}$ & $0.566^{*}$ & $0.527^{* *}$ & $0.648^{*}$ & $0.384 *$ \\
\hline$I Q 4$ & $0.467^{*}$ & $0.652 * *$ & $0.853^{* * *}$ & $2.229^{* *}$ & 0.261 & 0.415 & $1.023^{* *}$ & $0.813^{* *}$ & $0.689^{*}$ & 0.899 ** & 0.395 & 0.396 & $0.480^{* *}$ & $0.630 *$ & 0.287 \\
\hline$I Q 5$ & $0.526^{*}$ & $0.735^{* *}$ & $1.270^{* *}$ & $2.438^{* *}$ & 0.420 & $1.493^{* *}$ & $1.447 * *$ & $1.344^{* *}$ & 0.586 & $1.279^{* *}$ & 0.836 & $0.966^{* *}$ & $0.583^{* *}$ & $1.010^{* *}$ & $1.418^{*}$ \\
\hline$N$ & 762 & 1712 & 922 & 1481 & 297 & 844 & 828 & 1413 & 946 & 1897 & 870 & 801 & 1026 & 1243 & 1117 \\
\hline$P_{\text {seudo- }}{ }^{2}(\%)$ & 2.0 & 3.9 & 2.4 & 4.0 & 3.3 & 5.8 & 3.0 & 2.9 & 1.7 & 3.7 & 2.2 & 3.7 & 4.4 & 3.7 & 1.6 \\
\hline
\end{tabular}

Estimates of coefficients in ordered logit models for life satisfaction. * and ** denote significance at the $5 \%$ and $1 \%$ significance level, respectively. $N$ denotes the sample size. See Appendix 2 for more details on the explanatory variables. 
In most regressions the coefficients of age and its square are negative and positive, respectively, and in many these coefficients are significant. This implies a convex shape in the relationship of happiness or satisfaction with age. Happiness and satisfaction decrease with age to reach a minimum, increasing afterwards. The minimum is reached at different ages depending on the countries, but typically it occurs in the forties for happiness and life satisfaction and in the mid-thirties for financial satisfaction. Thus, for example, the coefficients of age and its square are always negative and positive, respectively, for Australia. They are also always significant at the $1 \%$ significance level. These values imply a "U" shape in the relationship of happiness or satisfaction with respect to age. The minimums are obtained at 46, 34 and 40 years for happiness, financial satisfaction and life satisfaction, respectively. It is interesting to note the ubiquity of this feature across countries. These results are in accordance with many contributions that also find this same pattern (see, for example, Oswald, 1997).

Bad health is strongly associated with unhappiness and dissatisfaction. In all cases the coefficient is negative, and in only three is it not significant. Having bad or very bad health substantially lowers well-being. This result is perfectly intuitive and agrees wholly with many studies conducted from very different fields that point to health as one of the main sources of happiness and satisfaction (Veenhoven, 1991).

In six countries women declare a significantly higher happiness than men, and in five countries a significantly higher life satisfaction. Therefore, there is some evidence of differences in happiness and life satisfaction according to sex, but it is not general. With regard to financial satisfaction, the results are not significant: in only one country is the difference in financial satisfaction between women and men significant at the $1 \%$ level; in the other countries the differences are of either sign.

The number of children does not seem to be an important factor of happiness or life satisfaction. However, in several countries, it seems to affect satisfaction negatively, especially financial satisfaction, due, perhaps, to the lower per capita income that children may imply in most households.

The marital status displays a strong association with happiness and satisfaction. In roughly half of the cases the variable MARRIED is significant, but, interestingly, in all these cases the sign of the coefficient is positive. It must be born in mind that people who are single form the reference category. Therefore, the evidence indicates that married people are often happier and more satisfied than bachelors. The difference frequently 
becomes stronger between married and widowed or between married and separated. This result is also in line with many contributions (see, for example, Argyle and Martin, 1991).

Aside from a few exceptions, size of town and the education level do not seem to affect happiness or satisfaction significantly.

Only UNEMPLOYED, among the variables that reflect labor characteristics has a significant effect on the dependent variables. Unemployment has a negative and significant effect on financial and life satisfaction in almost half of the countries, but, very surprisingly, has no significant influence on happiness in any country, though the estimates are mostly negative. This result is in sharp contrast to the evidence reported by many authors that point to unemployment as one of the main sources of unhappiness or dissatisfaction (Clark and Oswald, 1994, Gerlach and Stephan, 1996, Winkelmann and Winkelmann, 1998). ${ }^{1}$

Besides the variables examined above, the variables $I Q 2, I Q 3, I Q 4$ and $I Q 5$ have also been included in the regressions shown in Tables 2-4. As the reference category is composed by those that report to be in the first quintile of income, positive (negative) significant coefficients of IQ2,IQ3,IQ4 and IQ5 reflect higher (lower) happiness or satisfaction of being in the second, third, fourth and fifth income quintile, respectively, with respect to being in the first quintile. In addition to the comparison between the first and each of the other quintiles, it would be interesting to examine all the different pairs of quintiles. The results of these comparisons are presented in Tables 5, 6 and 7. They report the results of the tests of equal coefficients of the different quintiles in the equations of happiness, financial satisfaction and life satisfaction.

Not surprisingly, all the estimates accompanying $I Q 2, I Q 3, I Q 4$ and $I Q 5$ are positive in the models for financial satisfaction (see Table 2), and almost all of them are significant. Very similar results were obtained in the comparison of the other quintiles (see Table 6); in fact, almost eighty per cent of the comparisons yield significant differences. Therefore, income seems to be an important source of financial satisfaction. More interestingly, Tables 5 and 7 report the results of the tests of equal coefficients in the models for happiness and life satisfaction, respectively. With regard to this last variable, these tests also clearly

\footnotetext{
${ }^{1}$ Although these three contributions use the words 'unhappiness' or 'unhappy' in their titles, it is important to note that none of these papers use reported happiness. Clark and Oswald (1994) use mental distress, and Gerlach and Stephan (1996) and Winkelmann and Winkelmann (1998) use life satisfaction.
} 
indicate that income level is associated with life satisfaction. In most countries and for most income levels, richer individuals declare a higher life satisfaction. Nevertheless, the results for happiness are rather different. Roughly one third of the tests detect significant differences at the 5\% significance level. Therefore, the differences in happiness associated with income, though existing, are not so overwhelming as in financial or life satisfaction. In particular, striking differences across countries are obtained. While countries like China and Russia present many significant differences, this is not observed, for any income level, in countries like Peru, Spain or Venezuela. On the other hand, it is also interesting to note that the number of rejections of the null hypothesis decreases when medium and high levels of income are compared; thus, the comparisons between quintiles 3 and 4, 3 and 5, and 4 and 5, only yield five rejections. This can be interpreted as evidence in favor of a lower degree of association between income and happiness once a medium level of income is reached.

Table 5. Tests of equal coefficients of income quintiles in ordered logit models for happiness

\begin{tabular}{|l|l|l|l|l|l|l|l|l|l|l|}
\hline & $1-2$ & $1-3$ & $1-4$ & $1-5$ & $2-3$ & $2-4$ & $2-5$ & $3-4$ & $3-5$ & $4-5$ \\
\hline ARGENTINA & $0.03^{*}$ & $0.01^{*}$ & 0.13 & 0.10 & 0.79 & 0.80 & 0.98 & 0.62 & 0.81 & 0.84 \\
\hline AUSTRALIA & 0.36 & $0.00^{* *}$ & $0.01^{*}$ & $0.00^{* *}$ & $0.03^{*}$ & 0.10 & $0.03^{*}$ & 0.58 & 0.95 & 0.52 \\
\hline CHILE & 0.09 & $0.00^{* *}$ & $0.00^{* *}$ & $0.00^{* *}$ & $0.04^{*}$ & $0.00^{* *}$ & $0.01^{*}$ & 0.06 & 0.33 & 0.63 \\
\hline CHINA & $0.00^{* *}$ & $0.00^{* *}$ & $0.00^{* *}$ & $0.00^{* *}$ & $0.00^{* *}$ & $0.00^{* *}$ & $0.02^{*}$ & $0.00^{* *}$ & 0.38 & 0.60 \\
\hline DOMINICAN REP. & 0.37 & 0.25 & 0.50 & 0.58 & 0.80 & 0.90 & 0.22 & 0.71 & 0.14 & 0.26 \\
\hline FINLAND & 0.24 & $0.00^{* *}$ & 0.08 & $0.00^{* *}$ & $0.00^{* *}$ & 0.27 & $0.00^{* *}$ & 0.34 & 0.32 & 0.11 \\
\hline JAPAN & 0.29 & $0.01^{* *}$ & $0.00^{* *}$ & $0.00^{* *}$ & 0.08 & $0.03^{*}$ & $0.00^{* *}$ & 0.55 & $0.03^{*}$ & 0.14 \\
\hline NIGERIA & 0.54 & 0.83 & 0.25 & $0.01^{*}$ & 0.63 & $0.03^{*}$ & $0.00^{* *}$ & 0.07 & $0.00^{* *}$ & 0.08 \\
\hline PERU & 0.12 & 0.99 & 0.68 & 0.18 & 0.18 & 0.67 & 0.32 & 0.69 & 0.19 & 0.27 \\
\hline RUSSIA & $0.01 *$ & $0.00^{* *}$ & $0.00^{* *}$ & $0.00^{* *}$ & 0.68 & $0.00^{* *}$ & $0.00^{* *}$ & $0.00^{* *}$ & $0.00^{* *}$ & 0.08 \\
\hline SPAIN & 0.37 & 0.14 & 0.97 & 0.22 & 0.35 & 0.60 & 0.36 & 0.29 & 0.59 & 0.25 \\
\hline SWEDEN & $0.04 *$ & $0.01 *$ & $0.02^{*}$ & $0.02^{*}$ & 0.42 & 0.56 & 0.30 & 0.85 & 0.58 & 0.50 \\
\hline TAIWAN & 0.09 & 0.08 & $0.03^{*}$ & $0.00^{* *}$ & 0.92 & 0.62 & 0.12 & 0.70 & 0.16 & 0.30 \\
\hline USA & 0.60 & 0.23 & 0.30 & 0.10 & $0.01^{*}$ & $0.02^{*}$ & $0.00^{* *}$ & 0.80 & 0.43 & 0.24 \\
\hline VENEZUELA & 0.30 & 0.41 & 0.70 & 0.85 & 0.89 & 0.99 & 0.98 & 0.94 & 0.95 & 0.98 \\
\hline
\end{tabular}

$P$-values corresponding to the Wald tests of equal coefficients of the income quintiles indicated in the headings of the columns. $*$ and $* *$ indicate the rejections of equal coefficients at the $5 \%$ and $1 \%$ significance level, respectively. 
Table 6. Tests of equal coefficients of income quintiles in ordered logit models for financial satisfaction

\begin{tabular}{|l|l|l|l|l|l|l|l|l|l|l|}
\hline & $1-2$ & $1-3$ & $1-4$ & $1-5$ & $2-3$ & $2-4$ & $2-5$ & $3-4$ & $3-5$ & $4-5$ \\
\hline ARGENTINA & $0.00^{* *}$ & $0.00^{* *}$ & $0.00^{* *}$ & $0.00^{* *}$ & $0.00^{* *}$ & $0.00^{* *}$ & $0.00^{* *}$ & 0.74 & 0.09 & 0.20 \\
\hline AUSTRALIA & $0.00^{* *}$ & $0.00^{* *}$ & $0.00^{* *}$ & $0.00^{* *}$ & $0.00^{* *}$ & $0.00^{* *}$ & $0.00^{* *}$ & 0.28 & $0.00^{* *}$ & $0.00^{* *}$ \\
\hline CHILE & $0.00^{* *}$ & $0.00^{* *}$ & $0.00^{* *}$ & $0.00^{* *}$ & 0.41 & $0.00^{* *}$ & $0.00^{* *}$ & $0.02^{*}$ & $0.00^{* *}$ & $0.00^{* *}$ \\
\hline CHINA & $0.00^{* *}$ & $0.00^{* *}$ & $0.00^{* *}$ & $0.00^{* *}$ & $0.00^{* *}$ & $0.00^{* *}$ & $0.00^{* *}$ & $0.00^{* *}$ & $0.00^{* *}$ & $0.05^{*}$ \\
\hline DOMINICAN REP. & 0.30 & 0.06 & 0.22 & $0.00^{* *}$ & $0.00^{* *}$ & $0.03^{*}$ & $0.00^{* *}$ & 0.65 & $0.03^{*}$ & $0.01^{*}$ \\
\hline FINLAND & $0.00^{* *}$ & $0.00^{* *}$ & $0.00^{* *}$ & $0.00^{* *}$ & $0.01^{* *}$ & $0.01^{* *}$ & $0.00^{* *}$ & 0.58 & $0.00^{* *}$ & $0.01^{*}$ \\
\hline JAPAN & 0.33 & $0.00^{* *}$ & $0.00^{* *}$ & $0.00^{* *}$ & $0.00^{* *}$ & $0.00^{* *}$ & $0.00^{* *}$ & 0.17 & $0.00^{* *}$ & $0.00^{* *}$ \\
\hline NIGERIA & $0.00^{* *}$ & $0.00^{* *}$ & $0.00^{* *}$ & $0.00^{* *}$ & 0.16 & $0.00^{* *}$ & $0.00^{* *}$ & $0.00^{* *}$ & $0.00^{* *}$ & $0.00^{* *}$ \\
\hline PERU & $0.00^{* *}$ & $0.00^{* *}$ & $0.00^{* *}$ & $0.02^{*}$ & 0.05 & $0.00^{* *}$ & 0.12 & 0.06 & 0.30 & 0.84 \\
\hline RUSSIA & $0.00^{* *}$ & $0.00^{* *}$ & $0.00^{* *}$ & $0.00^{* *}$ & $0.00^{* *}$ & $0.00^{* *}$ & $0.00^{* *}$ & $0.01^{*}$ & $0.00^{* *}$ & $0.00^{* *}$ \\
\hline SPAIN & 0.16 & $0.00^{* *}$ & $0.00^{* *}$ & $0.00^{* *}$ & $0.00^{* *}$ & $0.00^{* *}$ & $0.00^{* *}$ & 0.31 & $0.03^{*}$ & 0.12 \\
\hline SWEDEN & $0.00^{* *}$ & $0.00^{* *}$ & $0.00^{* *}$ & $0.00^{* *}$ & $0.00^{* *}$ & $0.00^{* *}$ & $0.00^{* *}$ & $0.03^{*}$ & $0.00^{* *}$ & $0.00^{* *}$ \\
\hline TAIWAN & 0.44 & $0.03^{*}$ & $0.02^{*}$ & $0.00^{* *}$ & 0.15 & 0.10 & $0.00^{* *}$ & 0.85 & $0.01^{* *}$ & $0.01^{* *}$ \\
\hline USA & 0.08 & $0.00^{* *}$ & $0.00^{* *}$ & $0.00^{* *}$ & $0.00^{* *}$ & $0.00^{* *}$ & $0.00^{* *}$ & $0.04^{*}$ & $0.00^{* *}$ & $0.00^{* *}$ \\
\hline VENEZUELA & 0.17 & $0.00^{* *}$ & $0.00^{* *}$ & 0.23 & $0.03 *$ & $0.00^{* *}$ & 0.37 & 0.11 & 0.78 & 0.58 \\
\hline
\end{tabular}

$P$-values corresponding to the Wald tests of equal coefficients of the income quintiles indicated in the headings of the columns. $*$ and $* *$ indicate the rejections of equal coefficients at the $5 \%$ and $1 \%$ significance level, respectively.

Table 7. Tests of equal coefficients of income quintiles in ordered logit models for life satisfaction

\begin{tabular}{|c|c|c|c|c|c|c|c|c|c|c|}
\hline & $1-2$ & $1-3$ & $1-4$ & $1-5$ & $2-3$ & $2-4$ & $2-5$ & $3-4$ & $3-5$ & $4-5$ \\
\hline ARGENTINA & $0.01 *$ & $0.00 * *$ & $0.05^{*}$ & $0.03 *$ & 0.88 & 0.87 & 0.93 & 0.75 & 0.97 & 0.82 \\
\hline AUSTRALIA & $0.03 *$ & $0.00 * *$ & $0.00 * *$ & $0.00 * *$ & $0.03 *$ & $0.02 *$ & $0.00 * *$ & 0.85 & 0.46 & 0.54 \\
\hline CHILE & $0.00 * *$ & $0.00 * *$ & $0.00 * *$ & $0.00 * *$ & 0.71 & 0.14 & $0.00 * *$ & 0.25 & $0.01 * *$ & 0.06 \\
\hline CHINA & $0.00 * *$ & $0.00 * *$ & $0.00 * *$ & $0.00 * *$ & $0.00 * *$ & $0.00^{* *}$ & $0.00 * *$ & $0.00 * *$ & $0.02 *$ & 0.56 \\
\hline DOMINICAN REP. & 0.43 & \begin{tabular}{|l|}
0.90 \\
\end{tabular} & \begin{tabular}{|l|}
0.46 \\
\end{tabular} & 0.30 & \begin{tabular}{|l|}
0.51 \\
\end{tabular} & 0.14 & 0.10 & 0.36 & 0.23 & 0.69 \\
\hline FINLAND & $0.01 *$ & $0.00 * *$ & 0.12 & $0.00 * *$ & $0.01 *$ & $0.01 *$ & $0.00 * *$ & 0.07 & $0.05 *$ & $0.00 * *$ \\
\hline JAPAN & 0.08 & $0.00 * *$ & $0.00 * *$ & $0.00^{* *}$ & $0.00 * *$ & $0.00^{* * *}$ & $0.00 * *$ & 0.94 & $0.05^{*}$ & 0.05 \\
\hline NIGERIA & $0.00 * *$ & $0.01 * *$ & $0.00 * *$ & $0.00 * *$ & 0.91 & $0.03 *$ & $0.00 * *$ & $0.01 * *$ & $0.00 * *$ & $0.00 * *$ \\
\hline PERU & $0.01 * *$ & 0.17 & $0.01 *$ & 0.37 & 0.32 & 0.28 & 0.77 & 0.10 & 0.59 & 0.88 \\
\hline RUSSIA & $0.01 * *$ & $0.00 * *$ & $0.00 * *$ & $0.00 * *$ & $0.03 *$ & $0.00 * *$ & $0.00 * *$ & $0.01 * *$ & $0.00 * *$ & $0.03 *$ \\
\hline SPAIN & 0.33 & $0.04^{*}$ & \begin{tabular}{|l|}
0.17 \\
\end{tabular} & \begin{tabular}{|l|}
0.06 \\
\end{tabular} & 0.13 & 0.37 & 0.11 & 0.93 & 0.32 & 0.34 \\
\hline SWEDEN & 0.67 & $0.03 *$ & 0.14 & $0.01 * *$ & $0.01 * *$ & 0.12 & $0.00 * *$ & 0.34 & 0.15 & $0.04 *$ \\
\hline TAIWAN & $0.01 *$ & $0.00 * *$ & $0.01 * *$ & $0.00 * *$ & \begin{tabular}{|l|}
0.63 \\
\end{tabular} & 0.81 & 0.42 & 0.81 & 0.76 & 0.56 \\
\hline USA & 0.51 & $0.01 *$ & $0.01 *$ & $0.00 * *$ & $0.00 * *$ & $0.00^{* *}$ & $0.00 * *$ & 0.91 & $0.02 *$ & $0.01 * *$ \\
\hline VENEZUELA & 0.20 & $0.03 *$ & 0.38 & $0.03 *$ & \begin{tabular}{|l|}
0.18 \\
\end{tabular} & 0.69 & 0.05 & 0.77 & 0.11 & 0.10 \\
\hline
\end{tabular}

$P$-values corresponding to the Wald tests of equal coefficients of the income quintiles indicated in the headings of the columns. $*$ and $* *$ indicate the rejections of equal coefficients at the $5 \%$ and $1 \%$ significance level, respectively. 
This last point is related to a traditional result of international research. Many researchers agree that individuals are happier in richer countries, but that this relationship is not linear. Once a country reaches a certain economic level, the importance of economic conditions hardly affects happiness of individuals. The results here obtained suggest a similar 'intra-country' phenomenon. In light of the results for fifteen countries, the importance of income in happiness seems to diminish as income levels of individuals in a certain country attain medium and high levels.

Another important point that follows from Tables 2 and 4 is related to the differences in happiness and life satisfaction. As said above, the question on life satisfaction immediately followed the question on financial satisfaction, and, therefore, the response on life satisfaction could be conditioned by financial satisfaction. But it is interesting to note that, while non-economic conditions similarly affect happiness and life satisfaction, economic conditions show a rather different relationship with happiness and life satisfaction. Unemployment presents a strong and negative association with life satisfaction, but not with happiness. Income has a much more intense association with life satisfaction than with happiness. These findings point to happiness and life satisfaction as two distinct spheres of well-being. While the first would be independent of economic factors, they would clearly condition the second. As a result, one may think that changes in economic conditions (employment or income) decisively affect a certain sphere of subjective well-being (satisfaction), but have a much more limited effect on another (happiness).

Finally, two points must be noticed. Firstly, the ordered models that have been estimated above are very robust to alternative specifications. The conclusions hardly change when non-significant variables are excluded in the estimations for the different countries. Nor do they change when probit models are used instead of logit ones. Secondly, the relationships here analyzed must be understood as association relationships, not as causal relationships. It could be that some explanatory variables do not cause happiness and satisfaction of individuals, but, conversely, it is happiness and satisfaction of individuals that affect these explanatory variables. Though it seems improbable, the statistical methods that have been used do not allow excluding this possibility. 


\section{Conclusions}

Economic research has traditionally developed in a framework of revealed preferences and, consequently, has largely ignored the individuals' evaluations of their own satisfaction. This ignorance contrasts with the abundance of surveys where individuals quantify their happiness or satisfaction.

By using the World Values Survey conducted in 1995 and 1996, the present paper examines self-reported happiness, financial satisfaction and life satisfaction of individuals from 15 countries, relatively diverse from a socioeconomic perspective, from five continents. Some differences across countries are observed in these variables and there is some evidence that these differences are partially explained by the economic development of each country. The correlations between the different pairs of these three variables are clearly significant in all countries, and those between financial satisfaction and life satisfaction are often the highest.

To elucidate the socioeconomic factors associated with these variables, ordered logit models were estimated for each country. In spite of the socioeconomic, geographic and cultural differences across countries, there are sound similarities in the results of these estimations. The main conclusions are the following: i) age is an important factor in almost all countries, though not in a linear form; happiness and satisfaction typically present a parabolic shape with respect to age, and reach their minimum about the age of 40 years; ii) health shows a deep relationship with happiness and satisfaction; iii) marital status is also an important factor; married people are, usually, happier and more satisfied than those widowed and separated; iv) unemployment is significantly associated with financial and life satisfaction, but, surprisingly, does not seem to be so with happiness; iv) as expected, income holds a strong relationship with financial satisfaction; its relationship with life satisfaction and happiness is somewhat weaker, especially with this last variable, and presents both differences across countries and for levels of income. These results suggest the existence of two distinct spheres of well-being: happiness and satisfaction. Both are affected in a similar way by social conditions, but rather differently by economic conditions. 


\section{Appendix 1}

2.- Taking all things together, would you say you are:
1. Very happy
2. Quite happy
3. Not very happy
4. Not at all happy

20.- How satisfied are you with the financial situation of your household? If "1" means you are completely dissatisfied on this scale, and "10" means you are completely satisfied, where would you put your satisfaction with your household's financial situation?
1. Dissatisfied
2.
9.
10. Satisfied

21.- All things considered, how satisfied are you with your life as a whole these days?
1. Dissatisfied
2.
9.

10. Satisfied

101.- Here is a scale of incomes. We would like to know in what group your household is, counting all wages, salaries, pensions and other incomes that come in. Just give the letter of group your household falls into, before taxes and other deductions.
1. Lowest decile
2.
9
10. Highest decile 


\section{Appendix 2}

\section{- Explanatory Variables}

$A G E$ : Age of the individual in years.

$A G E^{2}$ : Square of $A G E$.

BADHEALTH: Dichotomous variable that takes value equal to 1 if the individual declares a poor or very poor state of health, and 0 otherwise.

WOMAN: Dichotomous variable that takes value equal to 1 if the individual is a woman, and 0 otherwise.

1CHILD, 2CHILDREN, 3CHILDREN, >3CHILDREN: Dichotomous variables that take value equal to 1 if the individual has $1,2,3$, or more than 3 children, respectively, and 0 otherwise.

MARRIED: Dichotomous variable that takes value equal to 1 if the individual is married, and 0 otherwise.

WIDOWED: Dichotomous variable that takes value equal to 1 if the individual is widowed, and 0 otherwise.

SEPARATED: Dichotomous variable that takes value equal to 1 if the individual is separated or divorced, and 0 otherwise.

TOWN2, TOWN3, TOWN4: Dichotomous variables that take value equal to 1 if the individual lives in a town whose population is comprised of between 10,000 and 100,000, between 100,000 and 500,000, or of more than 500,000 inhabitants, respectively, and 0 otherwise.

PRIMARY, SECONDARY, UNIVERSITY: Dichotomous variables that take value equal to 1 if the highest educational level that the individual has attained is primary school, secondary school, and university, respectively, and 0 otherwise.

PARTTIME: Dichotomous variable that takes value equal to 1 if the individual works part time, and 0 otherwise. 
SELFEMPLOYED: Dichotomous variable that takes value equal to 1 if the individual is self employed, and 0 otherwise.

HOUSEWIFE: Dichotomous variable that takes value equal to 1 if the individual is a housewife not otherwise employed, and 0 otherwise.

STUDENT: Dichotomous variable that takes value equal to 1 if the individual is a student, and 0 otherwise.

UNEMPLOYED: Dichotomous variable that takes value equal to 1 if the individual is unemployed, and 0 otherwise.

$I Q 2, I Q 3, I Q 4, I Q 5$ : Dichotomous variables that take value equal to 1 if the individual is in the second, third, fourth, or fifth quintile of income, respectively, and 0 otherwise.

\section{- Limitations of data}

The size of town was not available for Argentina and Finland. In Australia, Peru, the Dominican Republic, Sweden and the USA, as there were very few individuals without education, the reference category is formed by individuals without education or with primary school. In Chile, as no individual lived in a town with less than 10,000 inhabitants, and only two lived in towns with more than 500,000 inhabitants, the reference category is formed by individuals living in towns with less than 100,000 inhabitants, and TOWN4 was excluded. In Finland, as very few individuals had university-level education, UNIVERSITY was excluded. In Japan, the education level was not available, and, as no individual lived in towns with more than 100,000 inhabitants, TOWN3 and TOWN4 were excluded. In Sweden and Taiwan, as no individual lived in a town with more than 500,000 inhabitants, TOWN4 was excluded. 


\section{References}

Argyle, M. (1987), The psychology of happiness, Methuen, New York.

Argyle, M. and M. Martin (1991), The psychological causes of happiness, in Strack, F., M. Argyle and N. Schwarz, Subjective Well-Being, Pergamon Press, Oxford.

Blanchflower, D. and A.J. Oswald (2000), Well-being over time in Britain and the USA, mimeo.

Clark, A.E. and A.J. Oswald (1994), Unhappiness and unemployment, Economic Journal 104, pp. 648-659.

Di Tella, R., R.J. MacCulloch and A.J. Oswald (2001), Preferences over inflation and employment: Evidence from surveys of happiness, American Economic Review 91, pp. 335-341.

Easterlin, R.A. (1973), Does money buy happiness?, The Public Interest 30, pp. 3-10.

Easterlin, R.A. (1974), Does economic growth improve the human lot?, in David, P.A. and M.W. Reder, Nations and households in economic growth, Academic Press, New York.

Easterlin, R.A. (1995), Will raising the incomes of all increase the happiness of all?, Journal of Economic Behavior and Organization 27, pp. 35-47.

Frank, R.H. (1997), The frame of reference as a public good, Economic Journal 107, pp. 18321847.

Frey, B.S. and A. Stutzer (2000a), Happiness, economy and institutions, Economic Journal 110, pp. 918-938.

Frey, B.S. and A. Stutzer (2000b), Maximizing happiness?, German Economic Review 1, pp. 145167.

Gerlach, K. and G. Stephan (1996), A paper on unhappiness and unemployment in Germany, Economics Letters 52, pp. 325-330.

Holländer, H. (2001), On the validity of utility statements: standard theory versus Duesenberry's, Journal of Economic Behavior and Organization 45, pp. 227-249.

Kahneman, D., P.P. Wakker and R. Sarin (1997), Back to Bentham? Explorations of experienced utility, The Quarterly Journal of Economics 112, pp. 375-405

Lee, D.Y., S.H. Park, M.R. Uhlemann and P. Patsula (1999), What makes you happy?: A comparison of self-reported criteria of happiness between two cultures, Social Indicators Research 50, pp. 351-362.

Lewin, S.B. (1996), Economics and psychology: Lessons for our own day from the early twentieth century, Journal of Economic Literature 34, pp. 1293-1323. 
Myers, D.G. (1993), The pursuit of happiness, Aquarian, London.

Ng, Y.K. (1987), Relative-income effects and the appropriate level of public expenditure, Oxford Economic Papers 39, pp. 293-300.

Oswald, A.J. (1997), Happiness and economic performance, Economic Journal 107, pp. 1815-1831.

Pavot, W. and E. Diener (1993), Review of the satisfaction with life scales, Psychological Assessment 5, pp. 164-172.,

Sumner, L.W. (1996), Welfare, happiness and ethics, Clarendon Press, Oxford.

Veenhoven, R. (1989), National wealth and individual happiness, in Grunert K.G. and F. Ölander, Understanding economic behaviour, Kluwer Academic Publishers, Dordrecht.

Veenhoven, R. (1991), Questions on happiness: classical topics, modern answers, blind spots, in Strack, F., M. Argyle and N. Schwarz, Subjective Well-Being, Pergamon Press, Oxford.

Veenhoven, R. (2001), Are the Russians as unhappy as they say they are?, Journal of Happiness Studies 2, pp. 111-136.

Winkelmann, L. and R. Winkelmann (1998), Why are the unemployed so unhappy? Evidence from panel data, Economica 65, pp. 1-15. 